\title{
Influência do magnésio na resistência do arroz à mancha parda
}

\author{
Wiler Ribas Moreira (1); Renata Sousa Resende (2); Fabrício Ávila Rodrigues (2*); \\ Camila Cristina Lage Andrade ( $\left.{ }^{2}\right)$; Clístenes Williams Araujo Nascimento ( ${ }^{3}$ ) \\ (') Universidade Federal Rural de Pernambuco (UFRPE), Departamento de Fitopatologia, 52171-900 Recife (PE), Brasil. \\ (2) Universidade Federal de Viçosa (UFV), Departamento de Fitopatologia, 36570-000 Viçosa (MG), Brasil. \\ (3) UFRPE, Departamento de Agronomia, 52171-900 Recife (PE), Brasil. \\ (*) Autor correspondente: fabricio@ufv.br
}

Recebido: 15/jan./2013; Aceito: 16/abr./2013

\begin{abstract}
Resumo
A mancha parda, causada pelo fungo Bipolaris oryzae, é uma das principais doenças da cultura do arroz. Sabe-se que o magnésio $(\mathrm{Mg})$ tem o potencial de reduzir a intensidade de algumas doenças em culturas de importância econômica e, portanto, o objetivo desse trabalho foi verificar o efeito de diferentes doses desse macronutriente na resistência do arroz à mancha parda. Para isto, plantas de arroz (cv. Metica-1) foram cultivadas em solução nutritiva contendo 0,25; 0,5; 1; 2 e 4 mmol..-1 de Mg. Foram avaliados o período de incubação (PI), o número de lesões (NL) por $\mathrm{cm}^{2}$ de folha, a severidade da mancha parda e a concentração foliar de $\mathrm{Mg}$. Os dados de severidade foram usados para calcular a área abaixo da curva do progresso da mancha parda (AACPMP). Outro experimento com as doses de 0,25; 2,5 e 4 mmol.. ${ }^{-1}$ de $\mathrm{Mg}$ foi conduzido para determinar a concentração de aldeído malônico (MDA) e a atividade da quitinase (QUI), $\beta$-1,3-glucanase (GLU), peroxidase (POX), polifenoloxidase (PFO) e fenilalanina amônia-liase (FAL) em resposta à infecção por B. oryzae. Houve efeito linear positivo e linear negativo das doses crescentes de $\mathrm{Mg}$, respectivamente, na concentração foliar de Mg e na AACPMP. Houve efeito quadrático das doses crescentes de $\mathrm{Mg}$ no $\mathrm{PI}$ e no $\mathrm{NL}$ por $\mathrm{cm}^{2}$ de área foliar. Alta concentração de MDA e maior atividade da PFO ocorreram com a dose de 4 mmol. $\mathrm{L}^{-1}$ de $\mathrm{Mg}$. As atividades da QUI e da GLU não foram afetadas pelas doses de Mg. A maior atividade da POX ocorreu para as plantas supridas com as doses de 2,5 e 4 mmol..-1 de Mg. A FAL apresentou aumento significativo em atividade às 48 e 72 horas após inoculação com a dose de 4 mmol.L-1 $\mathrm{Mg}$. Os resultados desse estudo demonstram que a alta concentração foliar de $\mathrm{Mg}$ aumentou a resistência do arroz à infecção por B. oryzae principalmente por meio do aumento das atividades das enzimas de defesa.
\end{abstract}

Palavras-chave: Bipolaris oryzae, enzimas de defesa, nutrição mineral.

\section{Magnesium on rice resistance to brown spot}

\section{Abstract}

Brown spot, caused by the fungus Bipolaris oryzae, is one of the most important rice diseases. It is known that magnesium $(\mathrm{Mg})$ has the potential to decrease the intensity of some diseases in crops of economic importance. Therefore, the aim of this study was to determine the effect of different $\mathrm{Mg}$ rates on rice resistance to brown spot. Rice plants (cv. Metica-1) were grown in nutrient solution containing $0.25,0.5,1,2$ and 4 mmol. $\mathrm{L}^{-1} \mathrm{Mg}$. The incubation period (IP), the number of lesions $(\mathrm{NL})$ per $\mathrm{cm}^{2}$ of leaf, the brown spot severity, and the foliar concentration of $\mathrm{Mg}$ were evaluated. Data from severity were used to calculate the area under brown spot progress curve (AUBSPC). Another experiment with the rates of $0.25,2.5$ and $4 \mathrm{mmol} . \mathrm{L}^{-1} \mathrm{Mg}$ was carried out to determined the concentration of malondialdehyde (MDA) and the activity of chitinase (CHI), $\beta$-1,3-glucanase (GLU), peroxidase (POX), polyphenoloxidase (PPO) and phenylalanine ammonia-lyase (PAL) in response to $B$. oryzae inoculation. There were linear positive and linear negative effects of the $\mathrm{Mg}$ rates on the foliar concentration of $\mathrm{Mg}$ and AUBSPC. There was quadratic effect of the $\mathrm{Mg}$ rates on both IP and $\mathrm{NL}$ per $\mathrm{cm}^{2}$ of leaf area. The highest concentration of MDA and high PPO activity were obtained with the rate of $4 \mathrm{mmol} . \mathrm{L}^{-1} \mathrm{Mg}$. The activities of CHI and GLU were not affected by the $\mathrm{Mg}$ rates. High POX activity occurred for plants supplied with 2.5 and 4 mmol. $\mathrm{L}^{-1} \mathrm{Mg}$. Significant increase in PAL activity occurred at 48 and 72 hours after inoculation at the rate of $4 \mathrm{mmol} . \mathrm{L}^{-1} \mathrm{Mg}$. The results of this study demonstrated that the high foliar concentration of $\mathrm{Mg}$ increased rice resistance to infection by $\mathrm{B}$. oryzae mainly through the increase on the activities of defense enzymes.

Key words: Bipolaris oryzae, defense enzymes, mineral nutrition. 


\section{INTRODUÇÃO}

A mancha parda, causada pelo fungo Bipolaris oryzae (Breda de Haan) Shoemaker, é uma das doenças mais importantes da cultura do arroz (Ou, 1985). Nas folhas, os sintomas da mancha parda são lesôes irregulares de cor marrom avermelhado com um centro cinza e halo clorótico (Ou, 1985). Os danos associados à mancha parda são decorrentes da infecção pelo fungo nos grãos, da redução na germinação das sementes, da morte das plântulas originadas de sementes infectadas e da destruição da área foliar fotossinteticamente ativa (Ou, 1985). Alta incidência da mancha parda em folhas tem sido observada em plantas cultivadas em solos com deficiência de cálcio $(\mathrm{Ca})$, ferro $(\mathrm{Fe})$, magnésio $(\mathrm{Mg})$, manganês $(\mathrm{Mn})$, nitrogênio $(\mathrm{N})$, potássio (K) e silício (Si) (Kaur e Padmanabhan, 1974; Faria e Prabhu, 1983).

Os nutrientes podem, em deficiência ou excesso, diminuir ou aumentar a resistência das plantas à infecção por patógenos (Marschner, 1995). O Mg desempenha funçôes importantes na fisiologia vegetal por participar dos processos da fotofosforilação, da fixação fotossintética do dióxido de carbono, da síntese proteica, do carreamento do floema, da utilização dos fotoassimilados, na geração de espécies reativas de oxigênio e na foto-oxidação foliar (Hermans et al., 2005). Assim, vários processos fisiológicos e bioquímicos nas plantas podem ser alterados tanto pela deficiência quanto pelo excesso de $\mathrm{Mg}$ (Hermans et al., 2005). Além desses efeitos diretos do $\mathrm{Mg}$, a intensidade de doenças, dependendo da interação patógeno-hospedeiro, pode ser menor ou maior em função da concentração foliar de Mg (Huber, 1981). Woltz e Jones (1979) observaram que plantas de tomateiro e de pimentão supridas com altas doses de $\mathrm{Mg}$ foram mais suscetíveis a Xanthomonas campestris pv. vesicatoria. Porém, aplicaçóes de cloreto de magnésio com fertilizantes amoniacais em solos deficientes em $\mathrm{Mg}$ reduziu o mal-do-pé, causado por Gaeumannomyces graminis f.sp. tritici, em trigo (Huber, 1981).

Considerando a importância do $\mathrm{Mg}$ no metabolismo vegetal e a falta de informaçóes sobre o efeito desse elemento na interação arroz-Bipolaris oryzae, principalmente na potencialização da atividade de algumas enzimas de defesa, este trabalho teve como objetivo verificar o efeito de diferentes doses desse macronutriente em algumas variáveis epidemiológicas - período de incubação (PI), número de lesóes (NL) por $\mathrm{cm}^{2}$ de folha e severidade da mancha parda - e na potencialização da atividade de enzimas de defesa do arroz.

\section{MATERIAL E MÉTODOS}

Plantas de arroz (cultivar Metica-1), suscetível a Bipolaris oryzae foram crescidas em solução nutritiva de HoagLand e ArNon (1950) modificada, constituída de $1,0 \mathrm{mmol} \mathrm{L}^{-1}$ $\mathrm{KNO}_{3} ; 0,25 \mathrm{mmol} \mathrm{L}^{-1} \mathrm{NH}_{4} \mathrm{H}_{2} \mathrm{PO}_{4} ; 0,1 \mathrm{mmol} \mathrm{L}^{-1} \mathrm{NH}_{4} \mathrm{Cl}$; $1,0 \mathrm{mmol} \mathrm{L}-1 \mathrm{Ca}\left(\mathrm{NO}_{3}\right)_{2} ; 0,30 \mu \mathrm{mol} \mathrm{L}-1 \mathrm{CuSO}_{4} \cdot 5 \mathrm{H}_{2} \mathrm{O}$; $0,33 \mu \mathrm{mol} \mathrm{L} \mathrm{Z}^{-1} \mathrm{ZnSO}_{4} \cdot 7 \mathrm{H}_{2} \mathrm{O} ; 11,5 \mu \mathrm{mol} \mathrm{L} \mathrm{L}^{-1} \mathrm{H}_{3} \mathrm{BO}_{3}$; $3,5 \mu \mathrm{mol} \mathrm{L} \mathrm{MnCl}_{2} \cdot 4 \mathrm{H}_{2} \mathrm{O} ; 0,1 \mu \mathrm{mol} \mathrm{L} \mathrm{L}^{-1}\left(\mathrm{NH}_{4}\right)_{6} \mathrm{Mo}_{7} \mathrm{O}_{24} \cdot 4 \mathrm{H}_{2} \mathrm{O}$; $25 \mu \mathrm{mol} \mathrm{L}{ }^{-1} \mathrm{FeSO}_{4} .7 \mathrm{H}_{2} \mathrm{O}$ e $25 \mu \mathrm{mol} \mathrm{L}{ }^{-1}$ de ácido etilenodiaminotetracético (EDTA) bissódico. Para o experimento, visando estudar o efeito do $\mathrm{Mg}$ nos componentes epidemiológicos da mancha parda, as doses de $\mathrm{Mg}$ usadas foram de 0,$25 ; 0,5 ; 1 ; 2$ e $4 \mathrm{mmol} \mathrm{L}^{-1}$. Para as determinaçôes bioquímicas, utilizaram-se as doses de 0,25; 2,5 e $4 \mathrm{mmol} \mathrm{L}^{-1}$. Como fonte de $\mathrm{Mg}$, utilizou-se o $\mathrm{MgSO}_{4} \cdot 7 \mathrm{H}_{2} \mathrm{O}$. Para o preparo da solução nutritiva com a dose de $0,25 \mathrm{mmol} \mathrm{L}^{-1}$ de $\mathrm{Mg}$, utilizou-se $\mathrm{Na}_{2} \mathrm{SO}_{4}$ na concentração de $0,25 \mathrm{mmol} \mathrm{L}^{-1}$ e para a dose de $0,5 \mathrm{mmol} \mathrm{L}^{-1}$ de $\mathrm{Mg}$, utilizou-se o $\mathrm{MgSO}_{4} \cdot 7 \mathrm{H}_{2} \mathrm{O}$. Para as demais doses, utilizou-se o $\mathrm{MgCl}_{2}$ nas concentraçóes de $0,5,1,5$ e $3,5 \mathrm{mmol} \mathrm{L}^{-1}$ acrescido da dose de $0,5 \mathrm{mmol} \mathrm{L}^{-1}$ de $\mathrm{MgSO}_{4} .7 \mathrm{H}_{2} \mathrm{O}$. As sementes de arroz foram lavadas em solução de hipoclorito de sódio (10\%) por 1,5 minutos seguidas de lavagem em água deionizada por 3 minutos. As sementes foram germinadas em rolos de papel filtro embebidos com água e mantidos a $25^{\circ} \mathrm{C}$. Aos sete dias após germinação, seis plântulas foram transferidas para cada vaso plástico contendo cinco litros de solução nutritiva com as doses de $\mathrm{Mg}$. A solução nutritiva foi trocada a cada 4 dias ou quando a condutividade elétrica atingiu $85 \%$ do valor inicial. O pH da solução nutritiva foi verificado diariamente e mantido entre 5,5 e 6,0 com adição de soluções $1 \mathrm{M}$ de $\mathrm{HCl}$ ou $\mathrm{NaOH}$.

$\mathrm{O}$ isolado de $B$. oryzae (CNPAF HO-82) foi preservado em tiras de papel-filtro colocadas em tubos de vidro contendo sílica-gel e armazenados em geladeira a $4{ }^{\circ} \mathrm{C}$. Quinze dias antes da inoculação, foi feita a pré-multiplicaçáo do fungo em meio de cultura batata, dextrose e ágar (BDA). Quando a colônia atingiu $3 \mathrm{~cm}$ de diâmetro, a mesma foi repicada para novas placas de Petri contendo BDA e mantidas por 10 dias em câmara de crescimento tipo B.O.D $\left(25^{\circ} \mathrm{C}\right.$ e fotoperíodo de 12 horas). Foram adicionados $10 \mathrm{~mL}$ de água deionizada em cada placa de Petri e os conídios foram coletados com pincel de cerdas macias. A suspensão resultante foi homogeneizada e ajustada para a concentração de $1 \times 10^{4}$ conídios $\mathrm{mL}^{-1}$. Gelatina foi adicionada à suspensão $(1 \% \mathrm{~m} / \mathrm{v})$ para aumentar a aderência dos conídios na superfície foliar. As plantas foram inoculadas com B. oryzae quando emitiram a oitava folha no colmo principal conforme escala proposta por Matsou e Hoshikawa (1993) (aproximadamente 35 dias após emergência) com atomizador (VLS-Set Airbrush, Paache Airbrush Company, EUA). As seis plantas em cada vaso foram pulverizadas com $10 \mathrm{~mL}$ da suspensão de conídio. Após inoculação, as plantas foram mantidas em câmara de nevoeiro (temperatura de $25 \pm 2{ }^{\circ} \mathrm{C}$ e umidade relativa de $80 \pm 5 \%$ ) dentro da casa de vegetação. 
Visando estudar o efeito do $\mathrm{Mg}$ nos componentes epidemiológicos da mancha parda, o experimento foi instalado em delineamento inteiramente casualizado (DIC) com cinco tratamentos constituídos pelas cinco doses de $\mathrm{Mg}$ com cinco repetiçôes e foi repetido duas vezes. $\mathrm{O}$ experimento para as determinaçóes bioquímicas foi instalado em DIC em esquema fatorial 3 x 2 com 4 repetiçóes. Os fatores estudados foram doses de $\mathrm{Mg}$ e inoculação ou náo das plantas com $B$. oryzae.

A quinta e a sexta folha do colmo principal das plantas das repetições de cada tratamento foram marcadas e utilizadas para avaliar o PI, o NL por $\mathrm{cm}^{2}$ de folha e a severidade da mancha parda. O PI foi avaliado a cada três horas após inoculação (hai) das plantas, observando, com o auxílio de uma lupa (20X), o aparecimento dos sintomas da mancha parda. Às 48 hai, o NL por $\mathrm{cm}^{2}$ de folha foi contado com o auxílio de uma lupa (20X), em 4 áreas de $1 \mathrm{~cm}^{2}$ cada, aleatoriamente, nas folhas marcadas. A severidade da mancha parda foi avaliada às $24,48,72,96 \mathrm{e}$ 120 hai utilizando-se a escala proposta pelo International Rice Research Institute (IRRI) com valores de severidade variando de 0 a $100 \%$ (IRRI, 1996). Os valores obtidos foram utilizados para calcular a área abaixo da curva do progresso da mancha parda (AACPMP) de acordo com a fórmula proposta por SHANER e Finney (1977).

Para as análises bioquímicas, amostras da quinta e da sexta folha do colmo principal das plantas crescidas em solução nutritiva contendo apenas as doses de 0,$25 ; 2,5$ e $4 \mathrm{mmol} \mathrm{L}^{-1}$ de $\mathrm{Mg}$ foram coletadas às 24, 48, 72, $96 \mathrm{e}$ 120 hai. Folhas coletadas de plantas não inoculadas com B. oryzae $(0 \mathrm{~h})$ serviram como controle. As folhas foram mantidas em nitrogênio líquido durante as coletas e armazenadas em ultrafreezer a $-80^{\circ} \mathrm{C}$ até serem analisadas.

$\mathrm{O}$ extrato enzimático para determinar a atividade da quitinase (QUI, EC 3.2.1.14) foi obtido pela maceração de amostras de 0,3 g de tecido foliar com nitrogênio líquido em almofariz com adiçấo de polivinilpirrolidona (PVP) $1 \%(\mathrm{p} / \mathrm{v})$ até obtenção de um pó fino. $\mathrm{O}$ pó obtido foi homogeneizado em $2 \mathrm{~mL}$ de tampão fosfato de sódio $50 \mathrm{mM}$ (pH 6,5) contendo $1 \mathrm{mM}$ de fluoreto de fenilmetilsulfônico (PMSF) e $0,1 \mathrm{mM}$ de EDTA. O homogeneizado foi centrifugado a $20.000 \times \mathrm{g}$ por 25 minutos a $4{ }^{\circ} \mathrm{C}$ e o sobrenadante foi usado para as determinaçôes enzimáticas. A determinação da atividade da QUI foi realizada de acordo com a metodologia proposta por Roberts e Selitrennikoff (1988) modificada por Harman et al. (1993) utilizando o $p$-nitrofenil- $\beta$-D- $N$ $N^{N}$-diacetilquitobiose (PNP) (Sigma-Aldrich, São Paulo) como substrato. O meio de reação contendo $470 \mu \mathrm{L}$ de tampão acetato de sódio $50 \mathrm{mM}$ (pH 5,0), $10 \mu \mathrm{L}$ de PNP $\left(2 \mathrm{mg} \mathrm{mL}^{-1}\right)$ e $20 \mu \mathrm{L}$ do extrato vegetal foi incubado a $37^{\circ} \mathrm{C}$ por 2 horas. A reação foi paralisada acrescentando-se $500 \mu \mathrm{L}$ de carbonato de sódio 0,2 M (pH 5,0). As leituras de absorbância foram realizadas em espectrofotômetro a $410 \mathrm{~nm}$ imediatamente após as reaçôes serem paralisadas. A atividade da QUI foi determinada utilizando-se para os cálculos o coeficiente de extinção molar de $7 \times 10^{4} \mathrm{M}^{-1} \mathrm{~cm}^{-1}$ e expressa em $\mu \mathrm{M}$ de $p$-nitrofenil produzido por minuto por $\mathrm{mg}$ de proteína.

O extrato enzimático para determinar a atividade da $\beta$-1,3-glucanase (GLU, EC 3.2.1.6) foi semelhante ao obtido para determinação da QUI. A atividade da GLU foi determinada conforme metodologia descrita por LEVER (1972) com algumas modificaçóes. O ácido 3,5-dinitrosalicílico (DNS) foi usado em substituição à hidrazida do ácido $p$-hidroxibenzoico. O meio de reação foi constituído de $230 \mu \mathrm{L}$ de tampão acetato de sódio $100 \mathrm{mM}$ (pH 5,0), $250 \mu \mathrm{L}$ da solução do substrato laminarina $\left(4 \mathrm{mg} \mathrm{mL}^{-1}\right)$ e $20 \mu \mathrm{L}$ do extrato vegetal e incubado a $45^{\circ} \mathrm{C}$ por 30 minutos. Após esse período, foram acrescentados ao meio de reação $250 \mu \mathrm{L}$ de DNS e, em seguida, essa mistura foi aquecida a $100{ }^{\circ} \mathrm{C}$ por 5 minutos. Após o resfriamento em gelo até a temperatura de $30^{\circ} \mathrm{C}$, as amostras tiveram suas absorbâncias determinadas em espectrofotômetro a $540 \mathrm{~nm}$ e os resultados foram expressos em unidades de absorbância (Abs) por minuto por mg de proteína.

O extrato enzimático para determinação da atividade da peroxidase (POX, EC 1.11.1.7) foi obtido macerando $0,3 \mathrm{~g}$ de tecido foliar com $\mathrm{N}_{2}$ líquido em almofariz com adição de PVP $1 \%(\mathrm{p} / \mathrm{v})$ até obtenção de um pó fino. $\mathrm{O}$ pó obtido foi homogeneizado em $2 \mathrm{~mL}$ de tampão fosfato de sódio $50 \mathrm{mM}(\mathrm{pH} 6,5)$ contendo $1 \mathrm{mM}$ de PMSF e $0,1 \mathrm{mM}$ de EDTA. O homogeneizado foi centrifugado a $20.000 \times \mathrm{g}$ por 25 minutos a $4{ }^{\circ} \mathrm{C}$ e o sobrenadante foi usado para as determinaçōes enzimáticas. A atividade da POX foi determinada conforme metodologias propostas por Chance e Maehley (1955) e Kar e Mishra (1976). No ensaio colorimétrico, foram utilizados como substratos o pirogalol e o peróxido de hidrogênio. A mistura de reação foi composta por $340 \mu \mathrm{L}$ de água destilada, $250 \mu \mathrm{L}$ do tampão fosfato de potássio $100 \mathrm{mM}(\mathrm{pH}$ 6,8), $200 \mu \mathrm{L}$ de pirogalol $100 \mathrm{mM}, 200 \mu \mathrm{L}$ de peróxido de hidrogênio $100 \mathrm{mM} \mathrm{e} 10 \mu \mathrm{L}$ do extrato. As leituras de absorbância foram realizadas a $420 \mathrm{~nm}$ a cada 10 segundos durante 1 minuto em espectrofotômetro. A atividade da POX foi determinada utilizando-se para os cálculos o coeficiente de extinção molar de $2,47 \mathrm{mM}^{-1} \mathrm{~cm}^{-1}$ (CHANCE e MAehley, 1955) e expressa em mmol de purpurogalina produzida por minuto por $\mathrm{mg}$ de proteína.

O extrato enzimático para determinação da atividade da polifenoloxidase (PFO, EC 1.10.3.1) foi semelhante ao obtido para determinação da POX. A atividade da PFO foi determinada conforme metodologias propostas por Chance e Maehley (1955) e Kar e Mishra (1976). No ensaio colorimétrico, utilizou-se o pirogalol a $100 \mathrm{mM}$ como substrato. A mistura de reaçáo foi composta de $520 \mu \mathrm{L}$ de água destilada, $250 \mu \mathrm{L}$ do tampão fosfato de potássio $100 \mathrm{mM}(\mathrm{pH} \mathrm{6,8),} 200 \mu \mathrm{L}$ de pirogalol $100 \mathrm{mM} \mathrm{e}$ $30 \mu \mathrm{L}$ do extrato. As leituras de absorbância foram realizadas a $420 \mathrm{~nm}$ a cada 10 segundos durante 1 minuto em 
espectrofotômetro. A atividade da PFO foi determinada utilizando-se para os cálculos o coeficiente de extinção molar de 2,47 $\mathrm{mM}^{-1} \mathrm{~cm}^{-1}$ (Chance e Maehley, 1955) e expressa em $\mathrm{mmol} \mathrm{min}^{-1} \mathrm{mg}^{-1}$ proteína.

Para obtenção do extrato para determinação da atividade da fenilalanina amônia-liase (FAL, EC 4.3.1.5), $0,3 \mathrm{~g}$ de tecido foliar foi macerado com nitrogênio líquido em almofariz com adição de PVP (2\%) até obtenção de um pó fino. $\mathrm{O}$ pó obtido foi homogeneizado em $2 \mathrm{~mL}$ de tampão fosfato de sódio $50 \mathrm{mM}(\mathrm{pH}$ 6,5) contendo $1 \mathrm{mM}$ de PMSF e $0,1 \mathrm{mM}$ de EDTA. A mistura foi centrifugada duas vezes a $20.000 \mathrm{x} g$ por 25 minutos a $4^{\circ} \mathrm{C}$. O sobrenadante foi usado como substrato para determinar a atividade da FAL. A reação foi iniciada após adicionar $0,5 \mathrm{~mL}$ do extrato a uma mistura contendo $2 \mathrm{~mL}$ de tampão Tris- $\mathrm{HCl} 25 \mathrm{mM}(\mathrm{pH} 8,8)$ e $1 \mathrm{~mL}$ de $L$-fenilalanina $100 \mathrm{mM}$. A mistura de reação foi incubada em banho-maria a $30{ }^{\circ} \mathrm{C}$ durante 3 horas. Nas amostras controle, a $L$-fenilalanina foi substituído por $1 \mathrm{~mL}$ do tampão Tris- $\mathrm{HCl}$. A reação foi finalizada pela adição de $0,1 \mathrm{~mL}$ de $\mathrm{HCl} 6 \mathrm{~N}$. A absorbância dos derivados do ácido trans-cinâmico foi medida em espectrofotômetro a $290 \mathrm{~nm}$ e o coeficiente de extinção molar de $10^{4} \mathrm{mM}^{-1} \mathrm{~cm}^{-1}$ (ZuCKer, 1965) foi usado para calcular a atividade da FAL, a qual foi expressa em $\mathrm{mM} \mathrm{min}{ }^{-1} \mathrm{mg}^{-1}$ de proteína.

A concentração de proteínas em cada amostra foi determinada pelo método de BrADFORD (1976) e todas as determinações enzimáticas foram realizadas em triplicata.

Para determinar a concentração de aldeído malônico (MDA), 0,25 g de tecido foliar foram macerados em $\mathrm{N}_{2}$ líquido seguido de homogeneização em $2 \mathrm{~mL}$ de ácido tricloroacético (TCA) $(0,1 \% \mathrm{p} / \mathrm{v})$. O homogeneizado foi centrifugado a $10.000 \mathrm{x} g$ por 15 minutos a $4{ }^{\circ} \mathrm{C}$ e o sobrenadante foi coletado. Foram adicionados $500 \mu \mathrm{L}$ do sobrenadante em um tubo de microcentrífuga contendo $1,5 \mathrm{~mL}$ da solução de ácido tiobarbitúrico (TBA) $(0,5 \%)$ em TCA $20 \%$. As amostras foram incubadas por 2 horas a $90^{\circ} \mathrm{C}$ em banho-maria. A reação foi paralisada em banho de gelo por cinco minutos. As amostras foram centrifugadas a $13.000 \mathrm{x} g$ por 4 minutos. A absorbância da reação foi determinada em espectrofotômetro a $532 \mathrm{~nm}$. Utilizou-se para os cálculos, o coeficiente de absortividade molar de $155 \mathrm{mM}^{-1} \mathrm{~cm}^{-1}$ e os resultados foram expressos em $\mu$ mol de MDA por kg de matéria fresca.

Amostras de todas as folhas do colmo principal das plantas de cada tratamento foram coletadas, lavadas em água destilada e secadas em estufa com ventilação forçada de ar a $70^{\circ} \mathrm{C}$ até atingirem peso constante. Posteriormente, as folhas, sem bainha, foram moídas em moinho tipo Thomas-Wiley (Thomas Scientific, Swedesboro, NJ, EUA) com peneira de 20 mesh. A concentração foliar de $\mathrm{Mg}$ foi determinada por digestão nitroperclórica de acordo com Bataglia et al. (1983).

Os dados das variáveis $\mathrm{PI}$, o NL por $\mathrm{cm}^{2}$ de folha e AACPMP dos dois experimentos foram combinados após a verificação da homogeneidade de variância pelo teste de BARTLETt (GoMEz e GoMez, 1994), e submetidos à análise de variância e regressão polinomial.

Os dados das concentraçóes de MDA e de $\mathrm{Mg}$ e das atividades da QUI, GLU, POX, PFO e FAL foram submetidos à análise de variância e as médias comparadas pelo teste de Tukey ao nível de 5\% de probabilidade. Foi utilizado o software SAS (SAS Institute Inc., 1989, Cary, NC, EUA) para as análises estatísticas.

\section{RESULTADOS}

Houve efeito linear positivo das doses crescentes de $\mathrm{Mg}$ na concentração foliar desse macronutriente (Tabela 1). A variaçáo nos valores observados para a concentraçáo foliar de $\mathrm{Mg}$ da dose de $0,25 \mathrm{mmol} \mathrm{L}^{-1}$ para a dose de $4 \mathrm{mmol} \mathrm{L}^{-1}$ foi de 0,47 a $0,79 \mathrm{dag} \mathrm{kg}^{-1}$. Houve efeito quadrático das doses crescentes de $\mathrm{Mg}$ no PI e no $\mathrm{NL}$ por $\mathrm{cm}^{2}$ de área foliar (Tabela 1). A variação nos valores do PI e do NL por $\mathrm{cm}^{2}$ de área foliar da dose de $0,25 \mathrm{mmol} \mathrm{L}^{-1}$ para a dose de $4 \mathrm{mmol} \mathrm{L}^{-1}$, foram, respectivamente, de $18,35 \mathrm{a}$ 19,15 h e de 17,56 a 15,10 . Houve efeito linear negativo das doses crescentes de Mg na AACPMP (Tabela 1). A variaçấo nos valores da AACPMP da dose de $0,25 \mathrm{mmol} \mathrm{L}^{-1}$ para a dose de $4 \mathrm{mmol} \mathrm{L}^{-1}$ foi de 663,3 a 442,3 .

Houve efeito significativo dos fatores doses de $\mathrm{Mg}$ e épocas de coleta $(\mathrm{p} \leq 0,05)$ para as atividades das enzimas QUI, GLU, POX e PFO. Para a enzima FAL, o fator épocas de coleta foi significativo $(\mathrm{p} \leq 0,05)$. A interação doses de $\mathrm{Mg}$ x épocas de coleta foi significativa apenas para as atividades das enzimas QUI, POX e FAL ( $\mathrm{p}=0,0022$; 0,0034 e 0,0036 , respectivamente). Às 0 e 24 hai para a dose de $2,5 \mathrm{mmol} \mathrm{L}^{-1}$, a atividade da QUI foi significativamente maior em relaçáo as doses de 0,25 e $4 \mathrm{mmol} \mathrm{L}^{-1}$ (Figura 1a). Às 48 hai, não houve diferença significativa entre as doses de 2,5 e $4 \mathrm{mmol} \mathrm{L}^{-1}$ e nem entre as doses de 0,25 e $4 \mathrm{mmol} \mathrm{L}^{-1}$ às 72 hai para a atividade da QUI (Figura 1a). A atividade da QUI foi significativamente maior nas doses de 0,25 e 2,5 $\mathrm{mmol} \mathrm{L}^{-1}$ em relaçáo à dose de $4 \mathrm{mmol} \mathrm{L}^{-1}$ às 96 e 120 hai (Figura 1a). A atividade da GLU foi significativamente maior nas doses de 2,5 e $4 \mathrm{mmol} \mathrm{L}^{-1}$ em relaçáo à dose de $0,25 \mathrm{mmol} \mathrm{L}^{-1}$ às $0 \mathrm{e}$ 24 hai (Figura 1b). Não houve diferença significativa entre as 3 doses de $\mathrm{Mg}$ na atividade da GLU às 48 hai. A atividade da GLU foi significativamente maior nas doses de 4 e 2,5 $\mathrm{mmol} \mathrm{L}^{-1}$, respectivamente, às 72 e 120 hai (Figura 1b). Às 96 hai, a atividade da GLU foi significativamente maior nas doses de 0,25 e $2,5 \mathrm{mmol} \mathrm{L}^{-1}$ em relação à dose de $4 \mathrm{mmol}$ (Figura $1 \mathrm{~b}$ ). Nas plantas não inoculadas com $B$. oryzae, a atividade da POX foi significativamente maior na dose de $2,5 \mathrm{mmol} \mathrm{L}^{-1} \mathrm{em}$ relação a dose de $0,25 \mathrm{mmol} \mathrm{L}^{-1}$, mas não houve diferença significativa entre as doses de 2,5 e $4 \mathrm{mmol} \mathrm{L}^{-1}$ (Figura 1c). Não houve diferença significativa entre as 3 
doses de Mg na atividade da POX às 24 hai (Figura 1c). A atividade da POX foi significativamente maior às 48, 72 e 120 hai nas doses de 2,5 e $4 \mathrm{mmol} \mathrm{L}^{-1}$ em relação a dose de $0,25 \mathrm{mmol} \mathrm{L}^{-1}$ (Figura 1c). Às 96 hai, a atividade da POX foi significativamente maior na dose de $4 \mathrm{mmol}$ $\mathrm{L}^{-1}$ em relação às doses de 0,25 e $2,5 \mathrm{mmol} \mathrm{L}^{-1}$. Nas plantas não inoculadas com $B$. oryzae, a atividade da $\mathrm{PFO}$ foi significativamente maior na dose de $4 \mathrm{mmol} \mathrm{L}^{-1} \mathrm{em}$ relaçấo à dose de $0,25 \mathrm{mmol} \mathrm{L}^{-1}$, mas não houve diferença significativa entre as doses de 2,5 e $4 \mathrm{mmol} \mathrm{L}^{-1}$ (Figura $1 \mathrm{~d}$ ).
Tabela1. Equações de regressão da concentração foliar de magnésio, período de incubaçáo da mancha parda, número de lesóes por $\mathrm{cm}^{2}$ de folha e área abaixo da curva do progresso da mancha parda em plantas de arroz ao aumento de magnésio $\left(0,25 \mathrm{a} 4 \mathrm{mmol} \mathrm{L}^{-1}\right)$ na solução nutritiva

$\begin{array}{lc}\text { Variáveis } & \begin{array}{c}\text { Equações de regressão* } \\ \text { Mg (dag kg-1) }\end{array} \\ \mathrm{Y}=0,40+0,07 x ; R^{2}=0,96\end{array}$

Mg: magnésio; PI: período de incubaçāo; NL: número de lesōes; AACPMP: área abaixo da curva do progresso da mancha parda. ${ }^{*}$ Todas as equaçóes foram significativas $(\mathrm{p}=0,001)$.

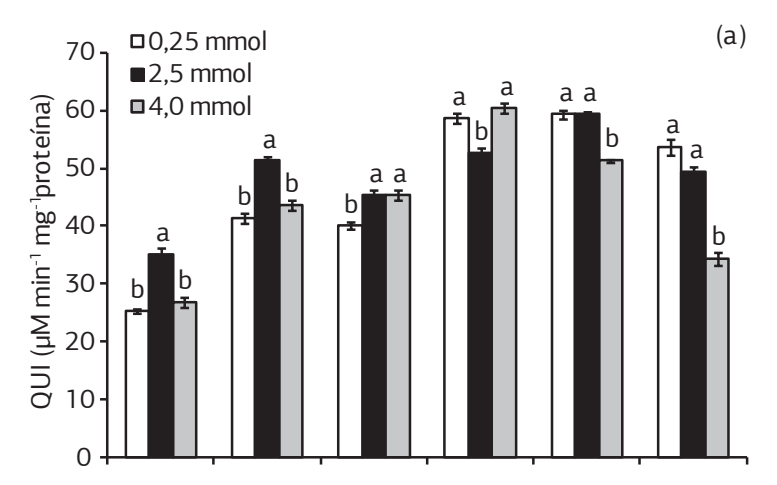

(c)
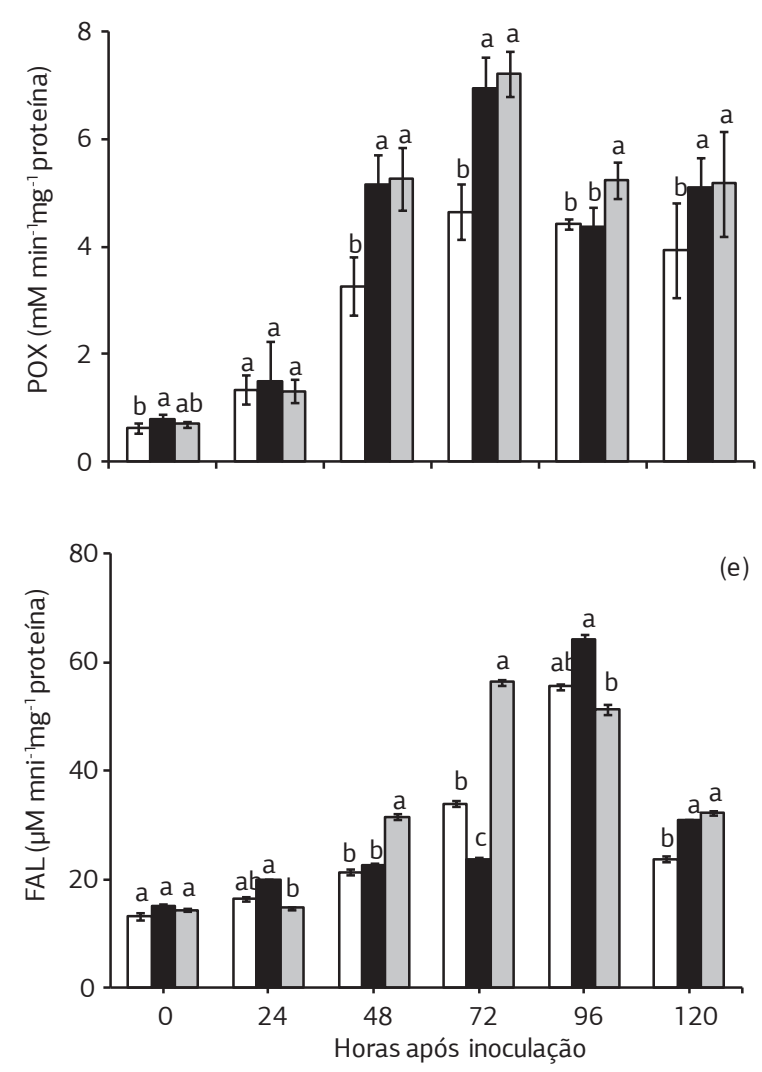

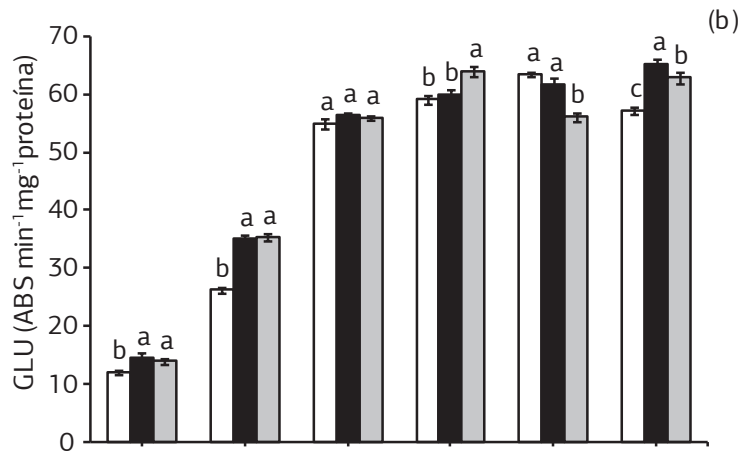

(d)
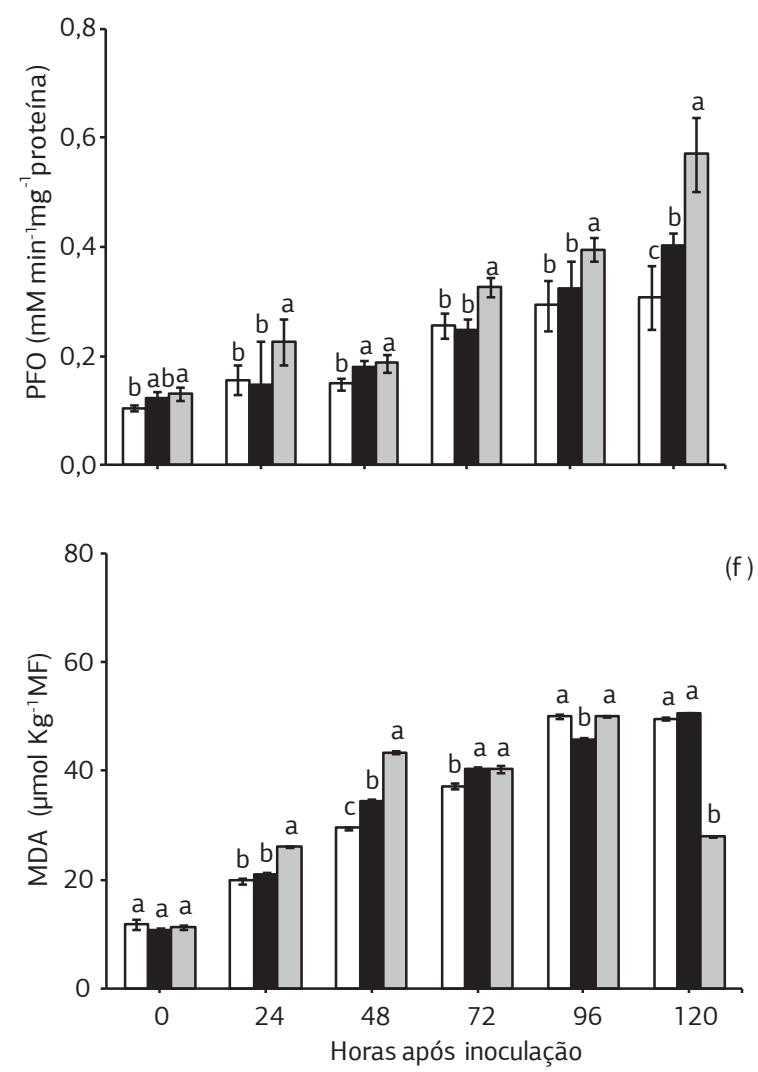

Figura 1. Atividades das enzimas (a) quitinase (QUI), (b), $\beta$-1,3-glucanase (GLU), (c) peroxidase (POX), (d) polifenoloxidase (PFO) e (e) fenilalanina amônia-liase (FAL) e concentração de (f) aldeído malônico (MDA) em folhas de plantas de arroz crescidas em solução nutritiva contendo três doses de magnésio e inoculadas com Bipolaris oryzae. Barras representam o desvio-padrão da média. Médias das três doses de magnésio, para cada época de avaliação, seguidas da mesma letra não são significativamente diferentes ( $\mathrm{p} \leq 0,05)$ pelo teste de Tukey. MF: matéria fresca; $\mathrm{n}=4$. 
A atividade da PFO foi significativamente maior na dose de $4 \mathrm{mmol} \mathrm{L}^{-1}$ em relaçáo as doses de 0,25 e $2,5 \mathrm{mmol} \mathrm{L}^{-1}$ às 24, 72, 96 e 120 hai (Figura 1d). Não houve diferença significativa entre as dose de 0,25 e $2,5 \mathrm{mmol} \mathrm{L}^{-1}$ na atividade da PFO às 24, 72 e 96 hai (Figura 1d). Às 120 hai, a atividade da $\mathrm{PFO}$ foi significativamente maior na dose de $4 \mathrm{mmol} \mathrm{L}^{-1}$ em relação às doses de 0,25 e $2,5 \mathrm{mmol} \mathrm{L}^{-1}$ (Figura 1d). Para a FAL, não houve diferença significativa entre as três doses de $\mathrm{Mg}$ nas plantas não inoculadas com B. oryzae (Figura 1e). Âs 24 hai, a atividade da FAL foi significativamente maior na dose de $2,5 \mathrm{mmol} \mathrm{L}^{-1}$ em relaçấo a dose de $4 \mathrm{mmol} \mathrm{L}^{-1}$. A atividade da FAL foi significativamente maior às 48 e 72 hai na dose de $4 \mathrm{mmol} \mathrm{L}^{-1}$ em relação às demais doses (Figura 1e). Às 96 hai, a atividade da FAL foi significativamente maior na dose de $0,25 \mathrm{mmol} \mathrm{L}^{-1}$ em relação à dose de 4 mmol L ${ }^{-1}$, mas não houve diferença significativa entre as doses de 2,5 e $4 \mathrm{mmol} \mathrm{L}^{-1}$ na atividade da FAL (Figura 1e). Às 120 hai, a atividade da FAL foi significativamente maior nas doses de 2,5 e $4 \mathrm{mmol} \mathrm{L}^{-1}$ de $\mathrm{Mg}$ em relação a dose de $0,25 \mathrm{mmol} \mathrm{L}^{-1}$ (Figura 1e).

Houve efeito significativo apenas dos fatores doses de $\mathrm{Mg}(\mathrm{p}=0.0001)$ e épocas de coleta $(\mathrm{p}=0.004)$ para a concentração de MDA. A concentração de MDA foi significativamente maior às $24,48 \mathrm{e} 72$ hai e significativamente menor às 120 hai para a dose de $4 \mathrm{mmol} \mathrm{L}^{-1}$ em relação a dose de 0,25 $\mathrm{mmol} \mathrm{L}^{-1}$ (Figura 1f).

\section{DISCUSSÃO}

$\mathrm{O}$ aumento na concentração foliar de $\mathrm{Mg}$ contribuiu para aumentar a resistência do arroz à mancha parda. A reduçáo na AACPMP nas plantas supridas com a maior dose de $\mathrm{Mg}$ demonstra a importância desse macronutriente na redução dos sintomas da mancha parda. $\mathrm{O}$ aumento do PI em função das doses crescentes de Mg é importante ao considerarmos que esse componente epidemiológico influencia a taxa de progresso da doença e, por conseguinte, a AACPMP. De acordo com Berger et al. (1997), quanto maior o PI e o período latente, menor será o número de ciclos secundários da maioria dos patógenos foliares e, consequentemente, menores intensidades das doenças. $\mathrm{O} N \mathrm{NL}$, outro componente epidemiológico avaliado neste estudo, foi reduzido pelas doses crescentes de $\mathrm{Mg}$ sugerindo, assim, que mecanismos de resistência poderiam estar restringindo a colonização dos tecidos foliares por B. oryzae. De acordo com BaвA (1958), o PI da mancha parda aumentou e o NL decresceu em plantas de arroz supridas com Mg. Por outro lado, plantas de tomateiro e de pimentão foram mais suscetíveis a Xanthomonas campestris pv. vesicatoria na presença de altas doses de $\mathrm{Mg}$ (Woltz e Jones, 1979).

As plantas são capazes de ativar rapidamente, mas de forma orquestrada, diferentes mecanismos bioquímicos de defesa associados com o metabolismo secundário após a infecção por patógenos. Assim, com o intuito de reforçar a hipótese de que o Mg estaria envolvido com uma resposta bioquímica de defesa do arroz à infecção por B. oryzae, estudou-se a atividade de algumas enzimas de defesa. Além disso, estudou-se a concentração de MDA, considerando que esse composto é marcador dos danos ocasionados às membranas induzidos por estresses bióticos e ou abióticos (Fu e Huang, 2001). De acordo com Dallagnol et al. (2011), houve aumento na concentração de MDA em folhas de arroz quando a severidade da mancha parda atingiu os maiores valores em comparaçáo com as plantas náo inoculadas. A produção de toxinas não específicas por $B$. oryzae, as quais podem causar danos na membrana plasmática (XIAO et al., 1991), pode colaborar para aumentar ainda mais a concentraçáo de MDA. Nas plantas inoculadas com $B$. oryzae, a maior concentraçáo de MDA foi obtida na dose de $4 \mathrm{mmol} \mathrm{L}^{-1} \mathrm{de} \mathrm{Mg}$, o que possivelmente pode ser explicado pelo fato de que altas concentraçóes citoplasmáticas de $\mathrm{Mg}$ bloqueiam os canais de $\mathrm{K}^{+}$na membrana interna dos cloroplastos desfavorecendo a remoçáo de $\mathrm{H}^{+}$do estroma que, por sua vez, resulta em maior concentração de espécies reativas de oxigênio e dano oxidativo celular (WU e Berkowitz, 1992; Venkatesan e Jayganensh, 2010).

A QUI e a GLU são responsáveis por degradar os principais carboidratos da parede celular dos fungos como a quitina e a $\beta$-1,3-glucano (MoHAmmadi et al., 2002). No presente trabalho, a atividade dessas enzimas não foi potencializada pelas maiores doses de $\mathrm{Mg}$, embora não deva ser descartado um possível efeito delas em afetar o crescimento de B. oryzae no tecido foliar. Segundo Rodrigues et al. (2005), a QUI não contribuiu para a resistência do arroz à brusone. Considerando que o PI aumentou e o NL reduziu para as plantas supridas com as maiores doses de $\mathrm{Mg}$, aventa-se para a hipótese de que, além da modesta participação das enzimas QUI e da GLU, outros mecanismos de defesa estejam envolvidos em restringir a colonização dos tecidos foliares de arroz por B. oryzae.

A POX está associada com a resistência das plantas à infecçáo por patógenos devido ao seu envolvimento na síntese de compostos fenólicos e lignina (Reimers et al., 1992). No entanto, a principal função desta enzima está relacionada com o metabolismo de espécies reativas de oxigênio (ERO) através da oxidação de substratos fenólicos, utilizando-se o peróxido de hidrogênio. No presente trabalho, a POX apresentou maior atividade nas plantas supridas com as doses de 2,5 e $4 \mathrm{mmol} \mathrm{L}^{-1} \mathrm{de} \mathrm{Mg}$. Isto indica uma possível açáo antioxidante dessa enzima na tentativa de eliminar as ERO produzidas em decorrência do processo infeccioso de B. oryzae. A PFO catalisa a hidroxilação dos monofenóis formando ortodifenóis e a oxidação desses em orto-quinonas com ação antimicrobiana (VAlero et al., 1988). A atividade da PFO aumentou à semelhança da POX, porém as maiores atividades ocorreram com a dose de $4 \mathrm{mmol} \mathrm{L}^{-1}$ de $\mathrm{Mg}$. 
A rota dos fenilpropanoides, iniciada pela conversão da $L$-fenilalanina a ácido trans-cinâmico, numa reação de desaminação catalisada pela enzima FAL, é importante para a produção de compostos fenólicos de natureza antimicrobiana, além de certas classes de fitoalexinas (Schuster e Rétey, 1995). No presente trabalho, a atividade da FAL apresentou aumento no início do processo infeccioso de $B$. oryzae nas plantas supridas com a dose de $4 \mathrm{mmol} \mathrm{L}^{-1} \mathrm{de} \mathrm{Mg}$, sugerindo um possível efeito do $\mathrm{Mg}$ em potencializar a atividade dessa enzima.

\section{CONCLUSÃO}

A alta concentração foliar de $\mathrm{Mg}$ é eficiente no controle da mancha parda, pois aumenta a resistência do arroz à infecção por $B$. oryzae, principalmente por meio do incremento das atividades das enzimas que atuam na defesa das plantas.

\section{AGRADECIMENTOS}

Ao Conselho Nacional de Desenvolvimento Científico e Tecnológico $(\mathrm{CNPq})$, à Fundação de Amparo à Ciência e Tecnologia do Estado de Pernambuco (FACEPE) e à Fundação de Amparo à Pesquisa do Estado de Minas Gerais (FAPEMIG) pelos recursos financeiros. Ao CNPq pela bolsa de Mestrado concedida a W.R.M. e pelas bolsas de Produtividade em Pesquisa de F.A.R. e C.W.A.N.

\section{REFERÊNCIAS}

BABA, I. Nutritional studies on the occurrence of Helminthosporium leaf spot and Akiochi of the rice plant. Bulletin of the National Institute of Agricultural Sciences Series, v.7, p.1-157, 1958.

BATAGLIA, O.C.; FURLANI, A.M.C.; TEIXEIRA, J.P.F.; FURLANI, P.R.; GALLO, J.R. Métodos de Análise Química de Plantas. Campinas: Instituto Agronômico. 1983. 48p. (Boletim Técnico, 78)

BERGER, R.D.; BERGAMIN FILHO, A.; AMORIM, L. Lesion expansion as an epidemic component. Phytopathology v.87, p.1005-1013, 1997. DOI: 10.1094/PHYTO.1997.87.10.1005

BRADFORD, M. A rapid and sensitive method for the quantification of microgram quantities of protein utilizing the principle of protein-dye binding. Analytical Biochemistry, v.72, p.248-254, 1976. DOI: 10.1006/abio.1976.9999

CHANCE, B.; MAEHLEY, A.C. Assay of catalases and peroxidases. Methods in Enzymology, v.2, p.764-775, 1955. DOI: 10.1016/S0076-6879(55)02300-8

DALLAGNOL, L.J.; RODRIGUES, F.A.; DAMATTA, F.M.; MIELLI, M.V.B.; PEREIRA, SC. Deficiency in silicon uptake affects cytological, physiological, and biochemical events in the rice-Bipolaris oryzae interaction. Phytopathology, v.101, p.92-104, 2011.

FARIA, J.C.; PRABHU, A.S. Relação entre fertilização nitrogenada e mancha-parda do arroz em solos de cerrado. Pesquisa Agropecuária Brasileira, v.18, p.1377-1379, 1983.

FU, J.; HUANG, B. Involvement of antioxidants and lipid peroxidation in the adaptation of two cool-season grasses to localized drought stress. Environmental and Experimental Botany, v.45, p.105-114, 2001. DOI: 10.1016/S0098-8472(00)00084-8

GOMEZ, K.A.; GOMEZ, A.A. Statistical Procedures for Agricultural Research, 2 ${ }^{\text {nd }}$ Edition, USA: Wiley, 1994.

HARMAN, G.E.; HAYES, C.K.; LORITO, M.; BROADWAY, R.M.; PIETRO, A.; PETERBAUER, C.; TRONSMO, A. Chitinolytic enzymes of Trichoderma harzianum: purification of chitobiosidase and endochitinase. Phytopathology, v.83, p.313-318, 1993.

HERMANS, C.; BOURGIS, F.; FAUCHER, M.; DELROT, S.; STRASSER, R.J.; VERBRUGGEN, N. Magnesium deficiency in sugar beet alters sugar partitioning and phloem loading in young mature leaves. Planta, v.220, p.541-549, 2005. DOI: 10.1007/ s00425-004-1376-5

HOAGLAND, D.R.; ARNON, D.I. The water culture method for growing plants without soils. Berkeley: Circular of the California Agricultural Experimental Station, v.347, p.1-32, 1950.

HUBER, D.M. The role of nutrients and chemicals. In: ASHER, M.J.C.; SHIPTON, P.J. (ed.). Biology and Control of Take-All. London: Academic Press Inc., 1981. p.317-341.

INTERNATIONAL RICE RESEARCH INSTITUTE (IRRI). Disease resistance. In: IRRI, Annual Report For. Los Baños, Philippines: International Rice Research Institute, 1996. p.36-53.

KAR, M.; MISHRA, D. Catalase, peroxidase, and polyphenoloxidase activities during rice leaf senescence. Plant Physiology, v.57, p.315319, 1976. DOI: $10.1104 /$ pp.57.2.315

KAUR, P.; PADMANADHAN, S.Y. Control of Helminsthosporium disease of rice with soil amendments. Current Science, v.43, p.8-9, 1974.

LEVER, M. A new reaction for colorimetric determination of carbohydrates. Analytical Biochemistry, v.47, p.273-279, 1972. DOI: 10.1016/0003-2697(72)90301-6

MARSCHNER, H. Mineral Nutrition of Higher Plants. $2^{\text {nd }}$ Edition. London: Academic Press, 1995.

MATSUO, T.; HOSHIKAMA, K. Science of the Rice Plant Morphology. Tokyo: Food and Agriculture Policy Research Center, 1993. 683p.

MOHAMMADI, M.; ROOHPARVAR, R.; TORABI, M. Induced chitinase activity in resistant wheat leaves inoculated with an incompatible race of Puccinia striiformis f.sp. tritici, the causal agent of yellow rust disease. Mycopathologia, v.154, p.119-126, 2002. DOI: 10.1023/A:1016039517933 
OU, S.H. Rice Diseases. $2^{\text {nd }}$ ed. Kew: Commonwealth Mycological Institute. 1985. p.109-201.

REIMERS, P.J.; GUO, A.; LEACH, J.E. Increased activity of a cationic peroxidase associated with an incompatible interaction between Xanthomonas oryzae pv. oryzae and rice (Oryza sativa). Plant Physiology, v.99, p.1044-1050, 1992. DOI: 10.1104/pp.99.3.1044

ROBERTS, W.K.; SELITRENNIKOFF, C.P. Plant and bacterial chitinases differ in antifungal activity. Journal of General Microbiology, v.134, p.169-176, 1988. DOI: 10.1099/00221287-134-1-169

RODRIGUES, F.A.; JURICK, W.M.; DATNOFF, L.E.; JONES, J.B.; ROLLINS, J.A. Silicon influences cytological and molecular events in compatible rice-Magnaporthe grisea interactions. Physiological and Molecular Plant Pathology, v.66, p.144-159, 2005. DOI: $10.1016 / j . p m p p .2005 .06 .002$

SCHUSTER, B.; RÉTEY, J. The mechanism of action of phenylalanine ammonia-lyase: the role of prosthetic dehydrolanine. Proceedings of the National Academy of Sciences of the United States of America, v.92, p.8433-8437, 1995. DOI: 10.1073/pnas.92.18.8433

SHANER, G.; FINNEY, R.E. The effect of nitrogen fertilization on the expression of slow-mildewing resistance in knox wheat. Phytopathology, v.67, p.1051-1056, 1977. DOI: 10.1094/ Phyto-67-1051
VALERO, E.; VARÓN, R.; GARCIA-CARMONA, F. Characterization of polyphenoloxidase from airen grape. Journal of Food Science, v.53, p.1482-1485, 1988. DOI: 10.1111/j.13652621.1988.tb09304.x

VENKATESAN, S.; JAYGANENSH, S. Characterisation of magnesium toxicity, its influence on amino acid synthesis pathway and biochemical parameters of tea. Research Journal of Phytochemistry, v.4, p.67-77, 2010. DOI: 10.3923/rjphyto.2010.67.77

WOLTZ, S.S.; JONES, J.P. Effects of magnesium on bacterial spot of pepper and tomato and on the in vitro inhibition of Xanthomonas vesicatoriaby streptomycin. Plant Disease Reporter, v.63, p.182-184, 1979.

WU, W.H.; BERKOWITZ, G.A. Stromal $\mathrm{pH}$ and photosynthesis are affected by electroneutral $\mathrm{K}^{+}$and $\mathrm{H}^{+}$exchange through chloroplast envelope ion channels. Plant Physiology, v.98, p.666672, 1992. DOI: 10.1104/pp.98.2.666

XIAO, J.Z.; TSUDA, M.; DOKE, N.; NISHIMURA, S. Phytotoxins produced by germinating spores of Bipolaris oryzae. Phytopathology, v.81, p.58-64, 1991. DOI: 10.1094/Phyto-81-58.

ZUCKER, M. Induction of phenylalanina deaminase by light and its relation to chlorogenic acid synthesis in potato tuber tissue. Plant Physiology, v.40, p.779-784, 1965. DOI: 10.1104/pp.40.5.779 